Disclosure of Interest: None declared

DOI: 10.1136/annrheumdis-2018-eular.4088

\section{THU0262 IDENTIFYING PATIENTS WITH AXIAL SPONDYLOARTHRITIS FROM A COHORT OF PATIENTS WITH CHRONIC BACK PAIN IN ORTHOPAEDICS CARE (AWARE STUDY)}

J. Braun $^{1}$, T. Mosch ${ }^{2}$, I. Fischer ${ }^{3}$, U. Kiltz ${ }^{1} .{ }^{1}$ Rheumazentrum Ruhrgebiet, Herne; ${ }^{2}$ Medical Affairs, AbbVie Deutschland GmbH and Co KG, Wiesbaden; ${ }^{3}$ BiostatistikTübingen, Tübingen, Germany

Background: Making an early diagnosis of axial spondyloarthritis (axSpA) has remained a challenge. The combination of clinical items suggestive of inflammatory back pain has proved useful for early identification of patients with axSpA in a pilot study in primary care. ${ }^{1}$ It has been shown that at least three of five features have a high prognostic impact.

Objectives: To evaluate the performance of these 5 clinical items (called AWARE criteria) to identify patients with axSpA from a large cohort of patients with chronic back pain in orthopaedics care.

Methods: In adult patients with chronic back pain ( $>3$ months) and age at onset of symptoms $<45$ years. who were concerned for referral to rheumatologists, the AWARE criteria were assessed and documented prior referring to the rheumatologists

Results: A total of 1306 patients (pts) first seen by orthopaedic surgeons were included. Of those, 500 pts were also seen by rheumatologists, and 188 (37.6\%) were diagnosed as ax $\mathrm{SpA}$, and, amongst others, $52.2 \%$ with non-specific back pain by clinical judgment. A total of 87 cases (17.4\%) were diagnosed with ankylosing spondylitis (AS) and 101 (20.2\%) with non-radiographic axSpA. A total of 206 pts fulfilled the ASAS classification criteria. The mean age of patients with axSpA was $38 \pm 11.5$ years, $46.2 \%$ were male, the mean duration of back pain was 94.1 \pm 103.6 months. The AWARE criteria had a sensitivity and specificity of $93.6 \%$ and $17.0 \%$ if $\geq 3$ criteria were chosen, and $6.3 \%$ and $83.0 \%$ with $<3$ criteria. In axSpA vs. non-axSpA pts, imaging (MRI or x-ray) was positive in $90.6 \%$ vs $9.4 \%$, HLA B27 in $69.4 \%$ vs $30.6 \%, 57.6 \%$ vs. $42.1 \%$ had a good response to NSAIDS, and an elevated CRP in $70.1 \%$ vs. $29.9 \%$. A minority of axSpA patients had arthritis $(5.6 \%)$, enthesitis $(6.2 \%)$, dactylitis (1\%), uveitis $(3.8 \%)$, psoriasis $(4.8 \%)$ and IBD (3.6\%). Positive imaging (MRI or $\mathrm{x}$-ray) resulted in the highest likelihood ratio (LR) for a diagnosis of axSpA. In combination with HLA B27 the LR was highest (127.1).

Conclusions: Even though the procedure of how patients were preselected in this study caused a selection bias for statistical analyses we think that this study confirms the usefulness of the original AWARE criteria to improve the identification of young patients with chronic back pain in primary care. The important role of imaging and HLA B27 was confirmed. In future studies the two-step approach with three clinical question first and then HLA B27 testing if necessary will be further investigated.

\section{REFERENCE:}

[1] Braun A, et al. Ann Rheum Dis 2011 Oct;70(10):1782-1787.

Disclosure of Interest: J. Braun Consultant for: AbbVie, Amgen, Biogen, Boehringer Ingelheim, BMS, Celgene, Celltrion, Centocor, Chugai, Epirus, Hospira, Janssen, Medac, MSD (Schering-Plough), Mundipharma, Novartis, Pfizer (Wyeth), Roche, Sanofi-Aventis, UCB., Speakers bureau: AbbVie, Amgen, Biogen, Boehringer Ingelheim, BMS, Celgene, Celltrion, Centocor, Chugai, EBEWE Pharma, Epirus, Hospira, Janssen, Medac, MSD (Schering-Plough), Mundipharma, Novartis, Pfizer (Wyeth), Roche, Sanofi-Aventis and UCB., T. Mosch Shareholder of: AbbVie Deutschland $\mathrm{GmbH}$ and Co. KG, Employee of: AbbVie Deutschland $\mathrm{GmbH}$ and Co. KG, I. Fischer Consultant for: AbbVie Deutschland GmbH and Co. KG, U. Kiltz Consultant for: AbbVie, Chugai, Grünenthal, Janssen, MSD, Novartis, Pfizer, Roche and UCB., Speakers bureau: AbbVie, Chugai, Grünenthal, Janssen, MSD, Novartis, Pfizer, Roche and UCB.

DOI: 10.1136/annrheumdis-2018-eular.1095

\section{THU0263 ANALYSIS ON CHARACTERISTICS OF 82 PATIENTS WITH ANKYLOSING SPONDYLITISIN JAPAN}

K. Tada ${ }^{1}$, S. Kobayashi ${ }^{2}$, E. Hayashi ${ }^{1}$, M. Ogasawara ${ }^{1}$, H. Inoue ${ }^{3}$, K. Yamaji ${ }^{1}$, N. Tamura ${ }^{1} .{ }^{1}$ Rheumatology and Internal Medicine, Juntendo University School of Medicine, hongo, bunkyo-ku; ${ }^{2}$ Internal Medicine, Juntendo Koshigaya Hospital, Koshigaya; ${ }^{3}$ Orthopaedic Surgery, Juntendo University School of Medicine, hongo, bunkyo-ku, Japan

Background: Ankylosing spondylitis (AS) is the prototype of spondyloarthritis, which affects sacroiliac joints, spine, peripheral joints and enthuses. HLA-B27 is known to be related with $A S$ and there is a considerable number of patients suffering from AS among other rheumatic diseases. In Japan, however, the prevalence of AS was reported to be less than $0.1 \%$ much lower than western countries and also other East Asian countries ${ }^{1)}{ }^{2)}{ }^{3)}$. This is due to the low frequency of HLA-B27 in Japanese $(0.3 \%)$ compared to $5 \%-10 \%$ in the countries mentioned above. Because of small number of AS patients, clinical features and HLA-B27 positivity has not been well investigated in Japanese patients with AS. Since our hospital has an outpatient specialising in AS and there are many patients, we conducted a survey on AS

Objectives: In this study, we examined the characteristics of patients with AS in our hospital and compared the data of patients with AS in Japan and overseas. Methods: We conducted a questionnaire survey on patients fulfilling the modified New York criteria for AS. A questionnaire included demographic data and histories. We also retrospectively investigated the data of blood test, radiographs and the presence of inflammatory back pain (IBP), HLA-B27, enthesitis, dactylitis, radiographic sacroiliitis and extra-articular manifestation.

Results: A total of 82 patients (82.9\% male) including Japanese (68), Chinese, ${ }^{9}$ Korean ${ }^{5}$ with AS who fulfilled the modified New York criteria were enrolled from May in 2013 to April in 2016. Of 68 patients with HLA-B27 test result, 61 patients (89.7\%) were HLA-B27 positive. Of 54 Japanese patients, 48 patients $(88.9 \%)$ were HLA-B27 positive. IBP, enthesitis, dactylitis, bamboo spine and uveitis were found in 67 patients $(81.7 \%), 31$ patients $(37.8 \%), 5$ patients $(6.1 \%), 44$ patients $(53.7 \%)$ and 30 patients $(36.6 \%)$, respectively.

Conclusions: In Japanese AS patients, the prevalence of HLA-B27 was high (almost 90\%) and other characteristics were similar with those of Western countries. In Japan where the frequency of HLA-B27 is very low, B27 positivity is considered to have high diagnostic value.

\section{REFERENCES:}

[1] Hukuda S, Minami M, Saito T, Spondyloarthropathies in Japan; Nationwide questionnaire survey performed by the japan ankylosing spondylitis society. J Rheumatol 2001;28: 554-559.

[2] Calin A, Fries JF. Striking prevalence of ankylosing spondylitis in "healthy" W27 positive males and gemales. N Engl J Med. 1975;293:835-839.

[3] Akkoc N, Khan MA. Overestimation of the prevalence of ankylosing spon dylitis in the Berlin study: comment on the article by Braun, et al. Arthritis Rheum 2005;52-4048-4049.

Disclosure of Interest: None declared

DOI: 10.1136/annrheumdis-2018-eular.3223

\section{THU0264 IMPACT OF EXTRA-ARTICULAR MANIFESTATIONS ON PATIENT-REPORTED OUTCOMES IN ANKYLOSING SPONDYLITIS AND PSORIATIC ARTHRITIS: INTERIM RESULTS FROM THE COMPLETE STUDIES}

L. Bessette $^{1}$, M. Khraishi' ${ }^{2}$, B. Florica ${ }^{3}$, Y. Setty ${ }^{4}$, M. Teo ${ }^{5}$, V. Remple ${ }^{6} .{ }^{1}$ Laval University, Centre Hospitalier de l'Université Laval, Quebec; ${ }^{2}$ Memorial University of Newfoundland, St. John's; ${ }^{3}$ University of Toronto, Toronto; ${ }^{4}$ Grey Bruce Health Services, Owen Sound; ${ }^{5}$ University of British Columbia, Penticton; ${ }^{6}$ AbbVie Corporation, Montreal, Canada

Background: Extra-articular manifestations (EAMs) in rheumatic diseases have been previously found to negatively impact health outcomes including quality of life and work capacity. Even though EAMs may be directly associated with worse response to treatment, differences in patient-reported outcomes (PROs) based on the presence of EAMs could be an important contributory variable.

Objectives: To assess the impact of EAMs on PROs among patients with active AS or PsA followed in Canadian routine clinical care.

Methods: Patients eligible for the COMPLETE studies are anti-TNF $\alpha$ naïve adults, with active AS or PsA per the judgment of the treating physician, who require change in their treatment regimen. In the current analysis patients enrolled between July/2011 - June/2017 were included. EAMs were defined as the pres ence of the following at baseline: enthesitis, uveitis, inflammatory bowel disease (IBD) or psoriasis $\left(E A M_{A S 1}\right.$ for $\left.A S\right)$; enthesitis, uveitis, or IBD $\left(E A M_{A S 2}\right.$ for $\left.A S\right)$ enthesitis or dactylitis (EAM $\mathrm{PsA}_{\mathrm{A}}$ for PsA). PROs included the Short Form Health Survey (SF-12), Work Limitations Questionnaire (WLQ) and Beck's Depression Inventory (BDI). PROs were compared between patients with and without EAMs using the independent samples t-test. The independent association between presence of EAMs and PROs at baseline was assessed with multivariate generalised linear models adjusting for disease state (high/very high vs. inactive/low/ moderate disease based on the BASDAI for AS and the DAS28 for PSA), disease type, and ever smoking

Results: A total of 609 AS and 406 PsA patients were included with a mean (SD) age of 43.1 (13.4) and 51.3 (12.3) years, respectively. $E_{A M_{A S 1}}$ and $E A M_{A S 2}$ prevalence among AS patients was $33.9 \%$ and $25 \%$, respectively, while among PsA patients $\mathrm{EAM}_{\mathrm{PsA}}$ prevalence was $45.4 \%$. 
In univariate analysis, presence of EAMs in AS was associated with significantly higher disease activity, BDI total score, WLQ mental interpersonal demands (only for $E_{A M_{1} 1}$ ), WLQ physical demands, WLQ time demands, SF-12 physical function, SF-12 role physical, SF-12 bodily pain, SF-12 vitality, SF-12 mental health (only for $E_{A M}$ ), and the SF-12 physical component summary score (PCS). Among PsA patients, patients with $\mathrm{EAM}_{\mathrm{PsA}_{\mathrm{A}}}$ had higher disease activity but no significant association was observed between EAMPsA and PROs.

Upon adjusting for disease state, disease type, and ever smoking, presence of $E_{A M_{1} /} / E A M_{P s A}$ for AS/PsA patients was associated with significantly higher BDI total score (14.0 vs. 12.6, $\mathrm{p}=0.046$ ) and lower SF-12 physical function (38.4 vs. $44.8, p=0.047)$. When evaluating the impact of $E A M_{A S 2} / E A M_{P s A}$ for $A S / P s A$ patients no significant differences were observed in PROs; however, BDI was notably higher among patients with EAMs (14.1 vs. 12.7, $\mathrm{p}=0.056$ ).

Conclusions: In a Canadian routine clinical care setting, a substantial proportion of $A S$ and PsA patients requiring a change in treatment report EAMs. Presence of EAMs, particularly psoriasis for AS patients, was found to be a significant independent predictor of depressive symptoms and reduced quality of life due to worse physical functioning.

Acknowledgements: JSS Medical Research, Montreal, Canada

Disclosure of Interest: L. Bessette Consultant for: Amgen, BMS, Janssen, Roche, UCB, AbbVie, Pfizer, Celgene, Lilly, Novartis, Speakers bureau: Amgen, BMS, Janssen, Roche, UCB, AbbVie, Pfizer, Merck, Celgene, Lilly, Novartis, M. Khraishi Consultant for: AbbVie, Speakers bureau: AbbVie, B. Florica Consultant for: for Roche, Abbvie, Pfizer, Janssen, Celgene, UCB, Speakers bureau: Janssen, Merck, Abbvie, Roche, BMS, Novartis, Y. Setty Consultant for: AbbVie, M. Teo Consultant for: AbbVie, Amgen, Celgene, Janssen, Merck, Novartis, Pfizer, Roche, Sanofi-Genzyme UCB, Speakers bureau: AbbVie, Roche, V. Remple Shareholder of: AbbVie, Employee of: AbbVie DOI: 10.1136/annrheumdis-2018-eular.3797

\section{THU0265 PATIENTS WITH AXIAL SPONDYLOARTHRITIS RARELY HAVE 1 OR 2 INFLAMMATORY BACK PAIN PARAMETERS}

M. de Hooge ${ }^{1,2}$, G.V. Varkas ${ }^{1,2}$, D. Elewaut ${ }^{1,2}$, F. van den Bosch ${ }^{1,2}$.

${ }^{1}$ Rheumatology, Ghent University Hospital; ${ }^{2}$ VIB Inflammation Research Centre, Ghent University, Gent, Belgium

Background: The Berlin Algorithm is a tool that assists clinicians in diagnosing axial spondyloarthritis (axSpA). In the modified Berlin Algorithm inflammatory back pain (IBP) is excluded as entry criterion. Although the modified Berlin Algorithm is used in clinical practice some argue that this modification insufficiently emphasises the inflammatory character of axSpA.

Objectives: The study aim was to provide an overview of the IBP parameters present in axSpA patients included in the Be-Giant cohort.

Methods: Data of an observational multicentre cohort study was used. Patients aged $\geq 18$ years with a new axSpA diagnosis and fulfilling the ASAS axSpA criteria were included in the Belgian inflammatory arthritis and spondylitis cohort (Be-Giant). All 5 IBP parameters used in the ASAS axSA classification criteria were collected during the clinical visit to the outpatient clinic. IBP parameters collected were: 1) Age at onset $<40$ years, 2) insidious onset, 3 ) improvement with exercise, 4) no improvement with rest and 5) pain at night. IBP is defined when $\geq 4$ of these parameters are present. Besides these 5 parameters also 'alternating buttock pain' and 'morning stiffness' are reported as these parameters are part of other IBP criteria then the ASAS criteria. All descriptive data was presented as $n(\%)$ or means $( \pm S D)$.

Results: All IBP parameters were collected from 228 patients and $49.6 \%(n=113)$ was male with mean age of 34.7 years (SD 9.7). Individual parameters were present in $>75 \%$ of the patients; the parameter 'age at onset $<40$ years' was present in $95.2 \%$, 'insidious onset' in $89 \%$, 'improvement with exercise' in $86 \%$, 'no improvement with rest' in $81.6 \%$ and 'pain at night' in $75.9 \%$ of the patients. There were 83 patients (36.4\%) with alternating buttock pain and 173 patients (75.9\%) with morning stiffness.

More than $80 \%$ of the patients (183/228) had IBP according to the ASAS criteria as they had $\geq 4$ IBP parameters. Patients rarely had 1 or 2 IBP parameters; $2(0.9 \%)$ patients with 1 parameter and $12(5.3 \%)$ patients with 2 parameters (table 1$)$.

Abstract THU0265 - Table 1. Total number of ASAS-IBP parameters in patients with axSpA diagnosis and classified according to the ASAS criteria in the Be-Giant cohort.

\begin{tabular}{lc}
\hline & Be-Giant cohort $\mathbf{n = 2 2 8}$ \\
\hline 0 IBP parameters & 0 \\
1 IBP parameters & $2(0.9 \%)$ \\
2 IBP parameters & $12(5.3 \%)$ \\
3 IBP parameters & $31(13.6 \%)$ \\
4 IBP parameters & $59(25.9 \%)$ \\
5 IBP parameters & $124(54.4 \%)$ \\
\hline IBP, inflammatory back pain. & \\
IBP parameters: Age onset back pain $<40$ years, insidious onset of back pain, improvement \\
with exercise, no improvement with rest, pain at night.
\end{tabular}

Conclusions: The majority of early axSpA patients had $\geq 4$ IBP parameters and therefore fulfilled the ASAS IBP criteria. A minority shows 1 or none IBP parameter. Hence, the inflammatory character of axSpA does not seem to subverted now that IBP is not a mandatory feature in classification of axSpA.

Disclosure of Interest: None declared

DOI: 10.1136/annrheumdis-2018-eular.4925

\section{THU0266 THE VALUE OF BELONGING TO PATIENTS' ASSOCIATION FOR AXIAL SPONDYLOARTHRITIS: RESULTS FROM THE ATLAS-2017}

M. Garrido-Cumbrera ${ }^{1,2}$, D. Gálvez-Ruiz ${ }^{1}$, E. Collantes Estevez ${ }^{3,4}$, C. Blanch Mur ${ }^{5}$ V. Navarro-Compán ${ }^{6} .{ }^{1}$ Universidad de Sevilla, Sevilla; ${ }^{2}$ CEADE, Madrid;

${ }^{3}$ Medicina, Universidad de Córdoba; ${ }^{4}$ Rheumatology, Hospital Universitario Reina

Sofía, Cordova; ${ }^{5}$ Novartis, Barcelona; ${ }^{6}$ Rheumatology, Hospital Universitario La

Paz, IdiPaz, Madrid, Spain

Background: International guidelines suggest that patients with axial spondyloarthritis (axSpA) become members of patient associations and self-help groups. However, the scientific evidence for this advice is limited and poor.

Objectives: To assess the relationship between membership of axSpA patient associations with regard to physical and psychological outcomes of the disease.

Methods: A sample of 680 axSpA patients was interviewed as part of the Spanish-2017 Atlas, which aimed to promote early referral, improve healthcare, and the use of effective treatments in patients with axSpA. By means of an online survey, the following self-reported data were collected: sociodemographic, smoking habits, degree of functional limitation in 18 daily activities (graded from 0-3 as none, little, some, moderate), spinal stiffness level at cervical, thoracic, and lumbar spine (0-3 none, little, some, moderate), disease activity through BASDAI (010), risk of severe psychiatric illness using General Health Questionnaire - GHQ$12(0-12)$, and treatment received (NSAIDs and biological therapy). Differences for all these variables between associated-patients and non-associated patients were tested, using Mann-Whitney or Chi-square tests.

Results: Out of 680 patients, $301(44.3 \%)$ were members of patient associations. Compared to non-associated patients, those associated were older, more frequently male, married, and few smoked (table 1). Additionally, despite having longer disease duration and receiving similar treatment, associated patients had lower disease activity (BASDAI 5.1 vs $5.8 ; p=0.001$ ), less functional limitation ( 26.5 vs $28.7 ; p<0.05$ ), and less risk of severe psychiatric illness (GHQ-12 4.9 vs $6.5 ; p<0.001)$

Abstract THU0266 - Table 1. Characteristics stratified by patient association membership status

\begin{tabular}{|c|c|c|c|}
\hline & $\begin{array}{c}\text { Associated } \\
\text { (mean } \pm \text { SD or } \\
\% \text { ) }\end{array}$ & $\begin{array}{c}\text { Non-Associated } \\
\text { (mean } \pm \text { SD or } \\
\% \text { ) }\end{array}$ & $\mathrm{P}$ \\
\hline Age (years) & $49.7 \pm 11.2$ & $42.4 \pm 9.4$ & $<0.001$ \\
\hline Gender (Male) & $57.8 \%$ & $39.3 \%$ & $<0.001$ \\
\hline Education Level (University) & $34.6 \%$ & $38.8 \%$ & 0.3 \\
\hline Marital Status (Married) & $79.1 \%$ & $65.4 \%$ & $<0.001$ \\
\hline Smoker & $32.6 \%$ & $41.6 \%$ & $<0.01$ \\
\hline Disease duration (years) $(n=555)$ & $26.0 \pm 12.4$ & $17.0 \pm 10.3$ & $<0.001$ \\
\hline $\begin{array}{l}\text { HLA-B27 (Positive) ( } \mathrm{n}=558) \\
\text { Treatment }\end{array}$ & $79.7 \%$ & $74.9 \%$ & 0.097 \\
\hline - NSAIDs (without biology) & $28.6 \%$ & $30.9 \%$ & 0.5 \\
\hline $\begin{array}{l}\text { - Biological (monotherapy or with } \\
\text { NSAIDs) }\end{array}$ & $39.2 \%$ & $34.0 \%$ & 0.2 \\
\hline BASDAI $(0-10)(n=442)$ & $5.1 \pm 2.1$ & $5.8 \pm 2.1$ & 0.001 \\
\hline $\begin{array}{l}\text { Stiffness } \\
\text {-Without Stiffness - low } \\
\text { - mild }\end{array}$ & $10.2 \%$ & $11.2 \%$ & $<0.01$ \\
\hline - high & $\begin{array}{l}17.6 \% \\
27.8 \% \\
44.5 \%\end{array}$ & $\begin{array}{l}20.0 \% \\
38.6 \% \\
30.2 \%\end{array}$ & \\
\hline $\begin{array}{l}\text { Functional Limitation } \\
(0-54)(n=605)\end{array}$ & $26.5 \pm 13.4$ & $28.7 \pm 12.9$ & 0.038 \\
\hline GQH-12 $(0-12)(n=474)$ & $4.9 \pm 4.5$ & $6.5 \pm 4.4$ & $<0.001$ \\
\hline
\end{tabular}

Conclusions: In axSpA, belonging to patient associations is related to better physical and psychological outcomes. Accordingly, rheumatologists should encourage patients to join these groups. However, further data on longitudinal studies is required to confirm these results.

Acknowledgements: The Atlas was promoted by CEADE and funded by Novartis

Disclosure of Interest: M. Garrido-Cumbrera: None declared, D. Gálvez-Ruiz: None declared, E. Collantes Estevez: None declared, C. Blanch Mur Employee of: Novartis, V. Navarro-Compán: None declared DOI: 10.1136/annrheumdis-2018-eular.7216 